\title{
PERKIRAAN PERMINTAAN PENUMPANG BANDAR UDARA BARU DI KEDIRI
}

\author{
Dwi Ardianta Kurniawan \\ Pusat Studi Transportasi dan \\ Logistik UGM \\ Jln. Kemuning M-3 Sekip \\ Sleman Yogyakarta 55281 \\ Tlp. (0274) 556928, 6491076 \\ dwiardianta@ugm.ac.id
}

\author{
Juhri Iwan Agriawan \\ Pusat Studi Transportasi dan \\ Logistik UGM \\ Jln. Kemuning M-3 Sekip \\ Sleman Yogyakarta 55281 \\ Tlp. (0274) 556928, 6491076 \\ iwanagriawan@ugm.ac.id
}

\author{
Hengki Purwoto \\ Pusat Studi Transportasi dan \\ Logistik UGM \\ Jln. Kemuning M-3 Sekip \\ Sleman Yogyakarta 55281 \\ Tlp. (0274) 556928, 6491076 \\ hengkipurwoto@ugm.ac.id
}

\begin{abstract}
This study aims to develop a method of calculating the passenger demand for new airport in Kediri, using secondary data, as part of the pre-feasibility study stage. The zone approach model is used in this study. The modeling results show that the potential passengers of the new Kediri Airport are between 571 thousand passengers, for the pessimistic scenario, up to 1.4 million passengers, for the optimistic scenario in 2020 . The results of this study are quite realistic when compared to the potential passengers at similar airports in Malang, East Java Province.
\end{abstract}

Keywords: airport; passenger; passenger demand; potential passengers.

\begin{abstract}
Abstrak
Kajian ini bertujuan untuk mengembangkan metode perhitungan permintaan penumpang bandar udara baru di Kediri, dengan memanfaatkan data sekunder, sebagai bagian tahapan prastudi kelayakan. Model zone approach digunakan pada kajian ini. Hasil pemodelan memperlihatkan bahwa potensi penumpang bandar udara baru Kediri adalah antara 571 ribu penumpang, untuk skenario pesimis, hingga 1,4 juta penumpang, untuk skenario optimis pada tahun 2020. Hasil kajian ini cukup realistis bila dibandingkan dengan potensi penumpang di bandar udara sejenis di Malang, Provinsi Jawa Timur.
\end{abstract}

Kata-kata kunci: bandar udara; penumpang; permintaan penumpang; potensi penumpang.

\section{PENDAHULUAN}

Moda angkutan udara memiliki pertumbuhan volume penumpang paling tinggi dibandingkan moda lainnya. Sebagai perbandingan, pada periode 1999-2016, penumpang angkutan udara tumbuh sebesar rerata $12,95 \%$ per tahun, sementara penumpang kereta api dan angkutan laut tumbuh masing-masing 3,58\% dan 1,09\% per tahun. Dari sisi besaran, moda jalan masih menjadi mayoritas dengan proporsi sebesar $85 \%$ angkutan penumpang dan 99\% angkutan barang (Leung, 2016). Moda angkutan udara memiliki volume penumpang 98,15 juta atau modal share sebesar 2,76\% terhadap total penumpang. Proporsi ini diperkirakan akan semakin besar di tahun-tahun mendatang melihat pertumbuhan penumpang angkutan udara yang pesat.

Menurut penggunaannya, sebagian besar bandar udara merupakan bandar udara domestik (87\%) dan bandar udara pengumpan atau feeder (86\%). Jumlah bandar udara di Indonesia, menurut kategori, disajikan pada Tabel 1. 
Tabel 1 Bandar Udara di Indonesia Menurut Kategori

\begin{tabular}{|c|c|c|c|c|c|c|}
\hline \multirow{2}{*}{ No. } & \multirow{2}{*}{ Kategori } & \multicolumn{4}{|c|}{ Tahun } & \multirow[b]{2}{*}{2018} \\
\hline & & 2014 & 2015 & 2016 & 2017 & \\
\hline \multirow[t]{4}{*}{1} & Bandar udara menurut penggunaannya & & & & & \\
\hline & - Internasional & 27 & 27 & 27 & 27 & 30 \\
\hline & - Internasional untuk Opensky & 5 & 5 & 5 & 5 & 5 \\
\hline & - Domestik & 210 & 264 & 264 & 266 & 235 \\
\hline \multirow[t]{5}{*}{2} & Bandar udara menurut hirarki & & & & & \\
\hline & - Pengumpul skala primer & 6 & 7 & 7 & 7 & 8 \\
\hline & - Pengumpul skala sekunder & 16 & 19 & 19 & 20 & 19 \\
\hline & - Pengumpul skala tersier & 13 & 8 & 9 & 10 & 10 \\
\hline & - Pengumpan feeder & 202 & 230 & 229 & 229 & 228 \\
\hline \multirow[t]{5}{*}{3} & $\begin{array}{l}\text { Bandar udara menurut kemampuan daya } \\
\text { dukung landas pacu }\end{array}$ & & & & & \\
\hline & $-1 \mathrm{~A} / 1 \mathrm{~B}$ & 69 & 107 & 102 & 62 & 66 \\
\hline & $-2 \mathrm{~B} / 2 \mathrm{C} / 2 \mathrm{D}$ & 55 & 48 & 47 & 59 & 64 \\
\hline & $-3 \mathrm{C} / 3 \mathrm{D}$ & 74 & 70 & 74 & 66 & 74 \\
\hline & $-4 \mathrm{C} / 4 \mathrm{D} / 4 \mathrm{E} / 4 \mathrm{~F}$ & 73 & 72 & 76 & 69 & 62 \\
\hline
\end{tabular}

Sumber: Kementerian Perhubungan (2018)

Jumlah bandar udara terbesar berada di Sumatera, yaitu 43 bandar udara (22,99\%), diikuti oleh Papua dan Papua Barat sebanyak 36 bandar udara (19,25\%) dan Kalimantan sebanyak 29 bandar udara (15,51\%). Jawa sebagai pusat kegiatan di Indonesia memiliki 16 bandar udara $(8,56 \%)$, sebagaimana disajikan pada Tabel 2.

Tabel 2 Jumlah Bandar Udara di Indonesia Per Wilayah

\begin{tabular}{lcr}
\hline \multicolumn{1}{c}{ Wilayah } & Jumlah & \multicolumn{1}{c}{$\%$} \\
\hline Sumatera & 43 & 22,99 \\
Jawa & 16 & 8,56 \\
Nusa Tenggara + Bali & 17 & 9,09 \\
Kalimantan & 29 & 15,51 \\
Sulawesi & 26 & 13,90 \\
Maluku & 20 & 10,70 \\
Papua + Papua Barat & 36 & 19,25 \\
Indonesia & 187 & 100,00 \\
\hline Sumber: Badan Pusat Statistik (2019)
\end{tabular}

Sumber: Badan Pusat Statistik (2019)

Tabel 3 Wilayah Layanan Bandar Udara

\begin{tabular}{|c|c|c|c|c|c|c|}
\hline \multirow[b]{2}{*}{ Wilayah } & \multicolumn{2}{|c|}{$\begin{array}{c}\text { Wilayah Layanan } \\
\text { Bandar udara }\end{array}$} & \multicolumn{2}{|c|}{ Total Wilayah } & \multicolumn{2}{|c|}{$\begin{array}{l}\text { \% Wilayah Layanan } \\
\text { per Total Wilayah }\end{array}$} \\
\hline & $\begin{array}{c}\text { Penduduk } \\
\text { (orang) }\end{array}$ & $\begin{array}{l}\text { PDRB } \\
(\mathrm{Rp} \mathrm{M})\end{array}$ & $\begin{array}{l}\text { Penduduk } \\
\text { (orang) }\end{array}$ & $\begin{array}{l}\text { PDRB } \\
(\mathrm{Rp} \mathrm{M})\end{array}$ & $\begin{array}{c}\% \\
\text { Penduduk }\end{array}$ & $\begin{array}{c}\% \\
\text { PDRB }\end{array}$ \\
\hline Sumatera & 17.534 .157 & 1.136 .480 & 57.026 .592 & 3.034 .769 & $30,7 \%$ & $37,4 \%$ \\
\hline Jawa & 24.485 .691 & 2.090 .577 & 152.419 .636 & 8.343 .491 & $16,1 \%$ & $25,1 \%$ \\
\hline Nusa Tenggara + Bali & 4.554 .920 & 102.764 & 10.243 .033 & 217.998 & $44,5 \%$ & $47,1 \%$ \\
\hline Kalimantan & 8.492 .387 & 639.875 & 16.264 .490 & 1.173 .080 & $52,2 \%$ & $54,5 \%$ \\
\hline Sulawesi & 7.975.394 & 424.363 & 19.835.193 & 870.870 & $40,2 \%$ & $48,7 \%$ \\
\hline Maluku & 3.286 .830 & 79.974 & 3.624 .332 & 87.636 & $90,7 \%$ & $91,3 \%$ \\
\hline Papua + Papua Barat & 4.442 .980 & 310.189 & 5.615 .595 & 344.338 & $79,1 \%$ & $90,1 \%$ \\
\hline Indonesia & 70.772 .359 & 4.784 .222 & 265.028 .871 & 14.072 .182 & $26,7 \%$ & $34,0 \%$ \\
\hline
\end{tabular}

Sumber: Badan Pusat Statistik (2019) 
Apabila dikaitkan dengan jumlah penduduk dan Produk Domestik Regional Bruto (PDRB) wilayah, dengan asumsi bahwa wilayah layanan berada dalam 1 kabupaten, dapat dilihat bahwa wilayah di Maluku dan Papua telah memiliki jangkauan layanan yang cukup tinggi, yaitu masing-masing 90,7\% dan $79,1 \%$. Hal ini dapat dilihat pada Tabel 3. Data tersebut menunjukkan bahwa wilayah Jawa memiliki persentase layanan yang relatif kecil. Hal ini wajar, karena wilayah di Jawa lebih padat dibandingkan dengan wilayah di luar Jawa, dengan kapasitas bandar udara yang lebih besar, sehingga wilayah layanan di Jawa mencakup beberapa kabupaten, bahkan lintas provinsi. Apabila dirinci lebih lanjut, bandar udara di Pulau Jawa berada pada provinsi-provinsi seperti yang terdapat pada Tabel 4.

Tabel 4 Wilayah Layanan Bandar Udara Provinsi di Jawa

\begin{tabular}{|c|c|c|c|c|c|c|c|}
\hline \multirow[t]{2}{*}{ Provinsi } & \multirow{2}{*}{$\begin{array}{c}\text { Jumlah } \\
\text { Bandar } \\
\text { udara }\end{array}$} & \multicolumn{2}{|c|}{$\begin{array}{l}\text { Wilayah Layanan } \\
\text { Bandar udara }\end{array}$} & \multicolumn{2}{|c|}{ Total Wilayah } & \multicolumn{2}{|c|}{$\begin{array}{c}\% \text { Wilayah } \\
\text { Layanan per Total } \\
\text { Wilayah }\end{array}$} \\
\hline & & $\begin{array}{l}\text { Penduduk } \\
\text { (orang) }\end{array}$ & $\begin{array}{l}\text { PDRB } \\
(\mathrm{Rp} M)\end{array}$ & $\begin{array}{l}\text { Penduduk } \\
\text { (orang) }\end{array}$ & $\begin{array}{l}\text { PDRB } \\
(\mathrm{Rp} \mathrm{M})\end{array}$ & Penduduk & PDRB \\
\hline DKI Jakarta & 1 & 2.892 .773 & 421.989 & 10.374 .217 & 2.414 .894 & $27,9 \%$ & $17,5 \%$ \\
\hline Jawa Barat & 3 & 3.993 .213 & 286.394 & 48.037 .885 & 1.812 .102 & $8,3 \%$ & $15,8 \%$ \\
\hline Jawa Tengah & 3 & 3.985 .393 & 307.982 & 34.257 .736 & 1.176 .484 & $11,6 \%$ & $26,2 \%$ \\
\hline DI Yogyakarta & 1 & 422.735 & 31.309 & 3.762 .157 & 119.300 & $11,2 \%$ & $26,2 \%$ \\
\hline Jawa Timur & 6 & 10.137 .403 & 846.327 & 39.293 .037 & 2.037 .174 & $25,8 \%$ & $41,5 \%$ \\
\hline Banten & 1 & 2.139 .891 & 149.420 & 12.448 .093 & 567.831 & $17,2 \%$ & $26,3 \%$ \\
\hline Jawa & 15 & 23.571 .408 & 2.043 .421 & 148.173 .125 & 8.127 .785 & $15,9 \%$ & $25,1 \%$ \\
\hline
\end{tabular}

Sumber: Badan Pusat Statistik (2019)

Data pada Tabel 4 menunjukkan bahwa Provinsi Jawa Timur memiliki persentase layanan yang tertinggi, baik dari sisi jumlah penduduk maupun dari aktivitas ekonomi. Namun demikian, potensi pasar bandar udara di Jawa Timur masih cukup potensial untuk dikembangkan. Hal ini dapat dilihat dari rencana pembangunan bandar udara di Kediri, yang akan dilakukan oleh PT Gudang Garam.

Salah satu tahap penting dalam perencanaan pembangunan infrastruktur skala besar adalah penentuan permintaan penumpang (demand), sebagai bagian perhitungan kelayakan finansial maupun kelayakan ekonomi. Dalam tahapan pembangunan bandar udara nantinya akan dilakukan survei secara detail untuk penentuan permintaan penumpang dengan berbasis pada data primer maupun data sekunder. Berbagai metode dapat digunakan, misalnya stated preferences, untuk melihat keinginan calon konsumen dalam menggunakan bandar udara dengan berbagai alternatif kualitas layanan. Pada tahap awal, kajian berdasarkan data sekunder dapat dilakukan untuk melihat potensi permintaan penumpang secara cepat, sebagai bagian prastudi kelayakan. Kajian ini diharapkan memberikan gambaran potensi permintaan penumpang secara cepat, namun memiliki dasar perhitungan yang dapat dipertanggungjawabkan. Hal ini penting, sehingga hasil perhitungan yang dihasilkan memiliki tingkat akurasi yang tinggi.

Tujuan penelitian ini adalah: (1) Mengembangkan metode perhitungan permintaan penumpang bandar udara baru berdasarkan pemanfaatan data sekunder sebagai bagian tahapan prastudi kelayakan; dan (2) Memberikan gambaran besaran permintaan penumpang 
bandar udara baru Kediri berdasarkan perhitungan cepat. Batasan masalah pada penelitian adalah: (1) Perhitungan didasarkan pada ketersediaan data sekunder, yang diperoleh dari Badan Pusat Statistik, baik berupa data asli maupun data terolah; (2) Wilayah layanan bandar udara baru Kediri memperhatikan jarak dan aksesibilitas yang diasumsikan meliputi beberapa kabupaten/kota, yaitu Kabupaten Trenggalek, Kabupaten Tulungagung, Kabupaten Blitar, Kabupaten Kediri, Kabupaten Nganjuk, Kota Kediri, dan Kota Blitar; dan (3) Jenis penumpang yang ditinjau adalah penumpang domestik.

\section{Perkiraan Permintaan Penumpang}

Perkiraan permintaan penumpang transportasi udara merupakan salah satu tahap penting dalam proses perencanaan sistem transportasi, yang ditentukan oleh karakteristik sosial ekonomi wilayah. Hasil perkiraan permintaan penumpang akan berpengaruh pada kebutuhan pengembangan infrastruktur, kinerja, dan tingkat penerimaan operator. Kesalahan perkiraan permintaan penumpang akan berakibat pada penggunaan infrastruktur maupun layanan yang tidak ekonomis, serta rendahnya kinerja sistem transportasi, karena kekurangan infrastruktur maupun tingkat layanan dibandingkan dengan permintaan penumpang aktual (Postorino, 2010).

Secara umum, model permintaan penumpang adalah hubungan matematis yang menghubungkan tingkat permintaan penumpang yang diharapkan (variabel dependen) dengan satu atau lebih variabel penjelas (variabel independen), yang sifatnya bergantung pada jenis model dan ketersediaan data yang sesuai. Pilihan untuk memulai perjalanan udara dari bandar udara tertentu bergantung pada banyak faktor, seperti aksesibilitas, fasilitas, layanan udara, dan tingkat konektivitas, yaitu tujuan yang dapat dicapai dari bandar udara itu sendiri. Aksesibilitas bergantung pada jaringan yang tersedia di wilayah tersebut, sedangkan faktor lain bergantung pada karakteristik bandar udara dan pasokan maskapai.

\section{Wilayah Layanan}

Untuk setiap bandar udara, area tangkapan biasanya ditentukan. Terdapat beberapa definisi untuk daerah tangkapan bandar udara, bergantung pada pertimbangan geografis atau pada pertimbangan permintaan penumpang. Dari sudut pandang geografis, area tangkapan suatu bandar udara dapat didefinisikan sebagai area yang berisi semua pengguna potensial dan penumpang bandar udara tersebut (Postorino, 2010). Dari sudut pandang permintaan penumpang, area tangkapan suatu bandar udara dapat didefinisikan sebagai jumlah penumpang yang menggunakan bandar udara tersebut, yang asal-usul penumpang dapat diidentifikasi di area sekitar bandar udara, yang ukurannya bergantung pada karakteristik bandar udara itu sendiri. Kedua sudut pandang tersebut pada akhirnya mengarah pada pengetahuan tentang permintaan penumpang dan wilayah geografis.

Identifikasi daerah tangkapan bandar udara yang mengikuti sudut pandang pertama atau kedua dapat dilakukan dengan menggunakan pendekatan dan model yang berbeda. Pada dasarnya, sudut pandang geografis diprediksi dengan menggunakan indikator, terutama indeks aksesibilitas, sedangkan sudut pandang permintaan penumpang diprediksi dengan 
menggunakan model perilaku. Identifikasi geografis dapat berguna untuk bandar udara yang belum dibangun, untuk memperkirakan potensi daya tarik bandar udara dalam hal aksesibilitas bagi pengguna yang tinggal di daerah sekitarnya, mengingat karakteristik bandar udara serta data pasokan maskapai belum tersedia.

Sudut pandang permintaan penumpang berguna untuk menentukan permintaan penumpang yang dipertimbangkan untuk memilih bandar udara tertentu berdasarkan karakteristik beberapa pilihan bandar udara. Probabilitas pengguna di setiap zona untuk memilih bandar udara bergantung pada karakteristik bandar udara itu sendiri dan bandar udara kompetitif, serta jarak atau aksesibilitas antara setiap zona dan bandar udara yang dipilih (Postorino, 2010). Kemudian, permintaan penumpang yang diperoleh di masing-masing bandar udara mewakili daerah tangkapan dari sudut pandang permintaan penumpang, sementara potensi geografisnya sesuai dengan daerah yang dikaji.

Selanjutnya, perbedaan dapat dibuat antara daerah tangkapan bandar udara primer dan bandar udara sekunder (Postorino, 2010). Untuk bandar udara tertentu, yang pertama merujuk pada penumpang udara yang memilih bandar udara itu karena 'tertawan' atau captive. Sedangkan yang kedua mengacu pada penumpang udara yang dapat memilih bandar udara itu, tetapi tidak tertawan dan lebih elastis sehubungan dengan pilihan bandar udara lain. Secara umum, area tangkapan sekunder adalah tipikal untuk bandar udara yang mempunyai maskapai penerbangan berbiaya rendah dan untuk kelas pengguna yang lebih sensitif terhadap harga.

Pengetahuan daerah tangkapan suatu bandar udara penting karena mewakili kemungkinan permintaan penumpang bandar udara dan potensi pengembangan bandar udara tersebut. Level permintaan penumpang dan area tangkapan bandar udara sangat bergantung satu sama lain dan aksesibilitas lahan memainkan peran penting. Faktor-faktor yang paling relevan dan memengaruhi ukuran daerah tangkapan bandar udara adalah: (1) populasi, (2) pendapatan rata-rata tahunan dan pendapatan keluarga rata-rata, (3) tingkat pekerjaan, dan (4) sektor pekerjaan. Jika 3 faktor pertama meningkat, jumlah penumpang udara akan meningkat, diiringi oleh daerah tangkapan udara. Sementara itu, distribusi sektor pekerjaan merupakan indikasi yang berguna untuk mengidentifikasi calon penumpang udara berdasarkan tujuan perjalanan, misalnya sebagai pelancong atau sebagai pebisnis.

\section{Model Permintaan Penumpang}

Model permintaan penumpang diklasifikasikan sebagai model agregat dan model disagregat, bergantung pada sifat data yang dirujuk ke variabel permintaan penumpang dan variabel penjelas. Jika variabel 'permintaan penumpang' dan variabel penjelas merujuk ke satu pengguna, model dikatakan sebagai model disagregat, sedangkan jika variabel 'permintaan penumpang' dan variabel penjelas merujuk pada kelompok pengguna yang homogen, model dikatakan sebagai model agregat. Model-model permintaan penumpang suatu bandar udara dapat dilihat pada Tabel 5. 
Tabel 5 Model Perhitungan Permintaan Penumpang Bandar Udara

\begin{tabular}{llll}
\hline Zone approach & $\begin{array}{l}\text { Multi-mode } \\
\text { models }\end{array}$ & $\begin{array}{l}\text { Stage models } \\
\text { (discrete choice) } \\
\text { Static models }\end{array}$ & $\begin{array}{l}\text { Competitive } \\
\text { Non-competitve }\end{array}$ \\
& $\begin{array}{l}\text { Uni-mode } \\
\text { models }\end{array}$ & $\begin{array}{l}\text { Stage models } \\
\text { (discrete choice) } \\
\text { Time series models }\end{array}$ & $\begin{array}{l}\text { Competitive } \\
\text { Non-competitve } \\
\text { Competitive } \\
\text { Non-competitve }\end{array}$ \\
$\begin{array}{l}\text { Airport pairs } \\
\text { approach }\end{array}$ & $\begin{array}{l}\text { Uni-mode } \\
\text { models }\end{array}$ & Static models & \\
\hline Sumber: Postorino & Time series models & $\begin{array}{l}\text { Competitive } \\
\text { Non-competitve }\end{array}$ \\
\hline
\end{tabular}

Selanjutnya, model permintaan penumpang dapat disebut sebagai: (1) model deskriptif atau perilaku sesuai dengan apakah terdapat hipotesis eksplisit tentang perilaku pengguna perjalanan; atau (2) model multi-mode atau uni-mode jika memungkinkan pembagian moda di antara beberapa mode alternatif atau hanya satu moda transportasi. Model multimode mengacu pada simulasi sistem transportasi secara keseluruhan, ketika banyak moda transportasi tersedia, misalnya kereta api, bus, mobil, dan pesawat udara, yang selanjutnya permintaan penumpang pada banyak moda transportasi tersebut dapat dihitung. Sebaliknya, model unimode memberikan perkiraan permintaan penumpang hanya untuk satu moda transportasi yang kemudian disimulasi sebagai bagian sistem transportasi keseluruhan, misalnya sistem transportasi udara.

\section{METODE PENELITIAN}

Berdasar kajian literatur, jenis bandar udara yang dikaji, tujuan kajian sebagai perencanaan strategis, serta ketersediaan data, model yang digunakan pada kajian ini adalah model zone approach-uni mode model-time series model-noncompetitive. Pendekatan kajian yang digunakan mengikuti suatu pola, seperti disajikan pada Gambar 1.

Dalam kajian ini, variabel yang digunakan meliputi: (1) variabel tidak bebas (Y), yaitu potensi penumpang pesawat udara; dan (2) variabel bebas (X), yaitu jumlah penduduk, Produk Domestik Regional Bruto (PDRB), dan tingkat modernitas (\% sektor tersier). Sektor tersier, yaitu perdagangan dan jasa, dipilih sebagai variabel bebas karena memberikan pengaruh terbesar dalam perjalanan melalui bandar udara dibandingkan dengan sektor lainnya. Data yang digunakan adalah yang berasal dari Statistik Perhubungan, Kementerian Perhubungan, dan Badan Pusat Statistik (BPS). Model yang digunakan adalah model ekonometrik, dengan persamaan:

$$
Y=a \cdot X_{1}^{\beta} X_{2}^{\gamma} \ldots X_{n}^{n}
$$


dengan:

$\mathrm{Y}=$ variabel tidak bebas;

$\mathrm{X}$ = variabel bebas;

$\gamma=$ konstanta; dan

$\mathrm{n}=$ koefisien variabel.

Validasi model dilakukan dengan memerhatikan parameter statistika, yaitu koefisien determinasi $\left(\mathrm{R}^{2}\right)$ dan tingkat signifikansi variabel $(\mathrm{t})$.

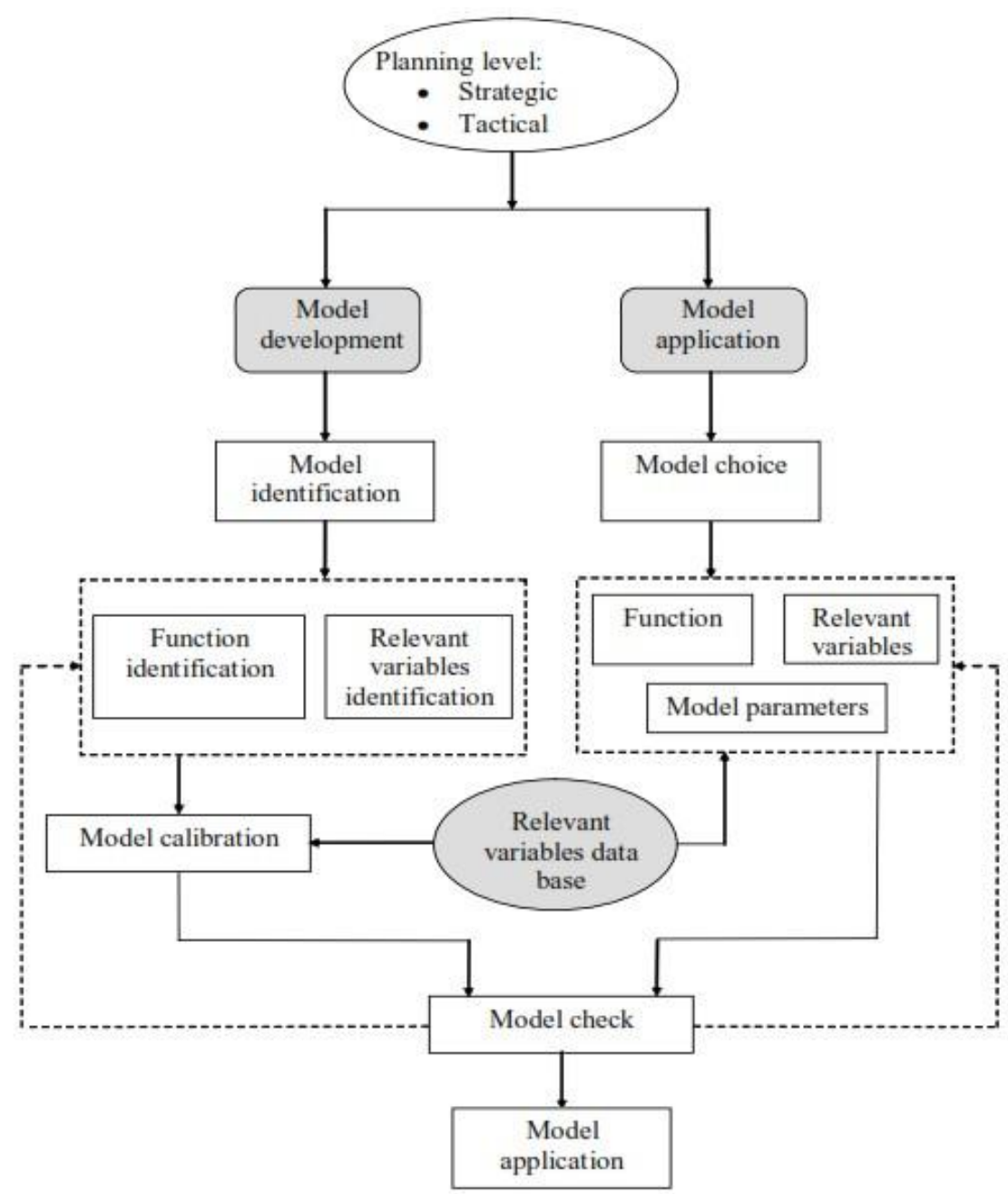

Sumber: Postorino (2010)

Gambar 1 Pengembangan Model dan Aplikasi

\section{HASIL DAN ANALISIS}

Data bandar udara yang digunakan adalah data bandar udara di seluruh Indonesia, yang dapat diklasifikasi dalam Jawa dan Luar Jawa, serta bandar udara komersial dan nonkomersial. Adapun data kewilayahan berbasis kabupaten. Identifikasi permintaan penumpang dapat berbasis pada wilayah administrasi maupun waktu tempuh ke lokasi bandar udara, 
sehingga dapat mencakup beberapa kabupaten/kota. Rentang waktu data yang digunakan adalah 3 tahun, yaitu tahun 2015, tahun 2016, dan tahun 2017. Dengan demikian, jenis data yang digunakan adalah data panel atau gabungan data antarwilayah (cross section) dengan runtun waktu (time series). Tabel 6 menunjukkan contoh sebagian data dasar yang digunakan dalam penyusunan model.

Tabel 6 Contoh Sebagian Data Dasar untuk Pemodelan

\begin{tabular}{|c|c|c|c|c|c|c|c|c|c|}
\hline \multirow{2}{*}{ Tahun } & \multirow{2}{*}{$\mathrm{Kab} / \mathrm{Kot}$} & \multirow{2}{*}{ Bandar udara } & \multicolumn{3}{|c|}{ Penumpang Domestik } & \multirow{2}{*}{$\begin{array}{c}\% \\
\text { sektor } \\
\text { tersier }\end{array}$} & \multirow{2}{*}{$\begin{array}{l}\text { PDRB } \\
\text { (T Rp) }\end{array}$} & \multirow{2}{*}{$\begin{array}{c}\text { Pdd } \\
\text { (ribu org) }\end{array}$} & \multirow{2}{*}{$\begin{array}{l}\text { PDRB p } \\
\text { (juta Rp) }\end{array}$} \\
\hline & & & Datang & Berangkat & Transit & & & & \\
\hline 2015 & Kota Kupang & Eltari & 752017 & 752753 & 18556 & 0,79 & 16,7 & 390,9 & 42,7 \\
\hline 2015 & Kota Pangkalpinang & Depati Amir & 812544 & 823775 & 22601 & 0,65 & 10,2 & 196,2 & 52,2 \\
\hline 2015 & Kota Malang & Abdul Rachman Saleh & 302819 & 310307 & 0 & 0,60 & 51,8 & 851,3 & 60,9 \\
\hline 2015 & Kota Jambi & Sultan Thaha Syarifuddin & 574043 & 594176 & 0 & 0,75 & 21,3 & 576,0 & 37,0 \\
\hline 2015 & Konawe Selatan & Wolter Monginsidi Haluoleo & 465843 & 478692 & 0 & 0,37 & 8,3 & 295,3 & 28,2 \\
\hline 2015 & Kota Palu & Mutiara SIS ALJufri & 514118 & 519254 & 4406 & 0,64 & 17,2 & 368,1 & 46,6 \\
\hline 2015 & Kota Ambon & Pattimura & 627988 & 583505 & 105928 & 0,85 & 11,1 & 411,6 & 26,8 \\
\hline
\end{tabular}

Sumber: Kementerian Perhubungan (2018)

Berdasarkan data tersebut disusun model permintaan penumpang angkutan udara dengan memperhatikan beberapa hal, seperti:

1) Kesetaraan potensi penumpang dengan rencana bandar udara baru di Kediri, sehingga data bandar udara yang digunakan dalam pemodelan adalah bandar udara dengan jumlah penumpang domestik kurang dari 1 juta per tahun di Indonesia, kecuali Papua dan Papua Barat. Wilayah Papua dan Papua Barat dikecualikan karena memiliki karakteristik wilayah dan kondisi sosial ekonomi yang berbeda dengan kondisi wilayah rencana bandar udara baru.

2) Variabel paling relevan dianalisis dengan memerhatikan tingkat signifikansi variabel hasil pemodelan.

Dengan memerhatikan hal-hal penting tersebut, model yang digunakan untuk memprediksi permintaan penumpang di bandar udara baru Kediri diragkum pada Tabel 7 dan Tabel 8.

Tabel 7 Model Jumlah Keberangkatan Penumpang Domestik

\begin{tabular}{lrrcrrr}
\hline \multirow{2}{*}{ Model } & \multicolumn{2}{c}{$\begin{array}{l}\text { Unstandardized } \\
\text { Coefficients }\end{array}$} & $\begin{array}{c}\text { Standardized } \\
\text { Coefficients }\end{array}$ & \multirow{2}{*}{ S } & Sig. \\
\cline { 2 - 4 } & \multicolumn{1}{c}{ B } & Std. Error & Beta & & \\
\hline 1 (Constant) & 2,008 & 2,869 & &, 755 &, 454 \\
LnPDRB & 1,101 &, 277 &, 408 & 3,594 &, 001 \\
LnSektor & 2,021 & 1,000 &, 402 & 3,534 &, 001 \\
\hline
\end{tabular}

a. Dependent Variable: Berangkat

Tabel 8 Model Jumlah Kedatangan Penumpang Domestik

\begin{tabular}{lrrrrr}
\hline \multirow{2}{*}{ Model } & \multicolumn{2}{c}{$\begin{array}{c}\text { Unstandardized } \\
\text { Coefficients }\end{array}$} & $\begin{array}{c}\text { Standardized } \\
\text { Coefficients }\end{array}$ & & Sig. \\
\cline { 2 - 4 } & \multicolumn{1}{c}{$\mathrm{B}$} & Std. Error & Beta & & \\
\hline 1 (Constant) & 2,054 & 3,057 & &, 609 &, 546 \\
LnPDRB & 1,093 &, 296 &, 398 & 3,450 &, 001 \\
LnSektor & 1,957 & 1,065 &, 397 & 3,445 &, 001 \\
\hline b. Dependent Variable: Datang & & &
\end{tabular}


Berdasarkan hasil pemodelan, variabel yang berpengaruh pada keberangkatan dan kedatangan adalah besaran PDRB dan persentase sektor sekunder, sementara variabel jumlah penduduk tidak berpengaruh secara signifikan. Perhitungan permitaan disimulasikan berdasarkan skenario-skenario pesimis, moderat, dan optimis, dengan dasar persentase jumlah penumpang yang diperkirakan mau menggunakan bandar udara baru, dengan ketentuan seperti yang disajikan pada Tabel 9.

Tabel 9 Skenario Pemodelan

\begin{tabular}{lcc}
\hline \multirow{2}{*}{ Skenario } & \multicolumn{2}{c}{$\%$} \\
\cline { 2 - 3 } & $\begin{array}{c}\text { Kota dan Kabupaten } \\
\text { Kediri }\end{array}$ & $\begin{array}{c}\text { Kabupaten/Kota } \\
\text { Lainnya }\end{array}$ \\
\hline Optimis & $100 \%$ & $75 \%$ \\
Moderat & $75 \%$ & $50 \%$ \\
Pesimis & $50 \%$ & $25 \%$ \\
\hline
\end{tabular}

Berdasarkan hasil pemodelan tersebut serta kecenderungan pertumbuhan PDRB dan sektor sekunder di wilayah layanan, yaitu Kabupaten Trenggalek, Kabupaten Tulungagung, Kabuoaten Blitar, Kabupaten Kediri, Kabuaten Nganjuk, Kota Kediri, dan Kota Blitar, ditentukan potensi penumpang domestik bandar udara baru Kediri untuk jangka waktu antara tahun 2020 hingga tahun 2040. Hasilnya dapat dilihat pada Tabel 10.

Tabel 10 Potensi Penumpang Domestik

\begin{tabular}{lrrrcc}
\hline Skenario & \multicolumn{1}{c}{2020} & \multicolumn{1}{c}{2025} & 2030 & 2035 & 2040 \\
\hline Optimis & 1.409 .835 & 2.125 .999 & 3.555 .475 & 5.951 .198 & 9.969 .597 \\
Moderat & 990.861 & 1.493 .856 & 2.497 .653 & 4.179 .671 & 7.000 .576 \\
Pesimis & 571.887 & 861.713 & 1.439 .831 & 2.408 .145 & 4.031 .554 \\
\hline
\end{tabular}

Hasil pemodelan memperlihatkan bahwa potensi jumlah penumpang bandar udara baru Kediri adalah antara 571 ribu (skenario pesimis) hingga 1,4 juta (skenario optimis) penumpang per tahun pada tahun 2020. Dengan memperhatikan pertumbuhan PDRB dan sektor sekunder, potensi penumpang meningkat hingga 4 juta pada tahun 2040 (skenario pesimis) hingga 9,9 juta penumpang (skenario optimis). Apabila dibandingkan dengan bandar udara setara di Jawa Timur, misalnya Bandar udara Abdurrahman Saleh di Malang, dengan jumlah penumpang 1.838.251 penumpang per tahun, besaran permintaan penumpang tersebut relatif cukup realistis.

\section{KESIMPULAN}

Dari penelitian yang telah dilakukan dapat ditarik kesimpulan sebagai berikut:

1) Hasil pemodelan pada studi ini memperlihatkan bahwa potensi penumpang bandar udara baru Kediri adalah antara 571 ribu (skenario pesimis) hingga 1,4 juta (skenario optimis) penumpang pada tahun 2020 . 
2) Hasil kajian ini cukup realistis bila dibandingkan dengan potensi penumpang di bandar udara yang setara di Provinsi Jawa Timur, misalnya Bandar Udara Abdurrachman Saleh, di Malang.

\section{UCAPAN TERIMA KASIH}

Terima kasih disampaikan kepada Manajemen Pusat Studi Transportasi dan Logistik (Pustral) UGM, yang telah memfasilitasi data dan informasi, sehingga kajian ini dapat dilaksanakan.

\section{DAFTAR PUSTAKA}

Badan Pusat Statistik. 2019. Statistik Transportasi Udara 2018. Jakarta.

Kementerian Perhubungan. 2018. Statistik Perhubungan Buku I 2018. Jakarta.

Leung, K.H. 2016. Indonesia's Summary Transport Assessment. ADB Papers on Indonesia. Metro Manila: Asian Development Bank.

Postorino, M.N. 2010. Air Demand Modelling: Overview and Application to A Developing Regional Airport. WIT Transactions on State of the Art in Science and Engineering, 38: 77-108. doi:10.2495/978-1-84564-143-6/04. 